\title{
Is it just about the crime? A psychological perspective on South African emigration
}

\author{
Maria C. Marchetti-Mercer \\ Department of Psychology, University of Pretoria, South Africa \\ Maria.Marchetti-Mercer@wits.ac.za
}

Various economic and socio-political reasons are usually given to explain people's decisions to emigrate from South Africa, and violent crime is often cited as the most compelling factor. By contrast, little attention has been paid to the psychological context within which the decision to emigrate is made. In this article, the experiences of ten South Africans prior to their emigration from South Africa are discussed. This qualitative study formed part of a larger research project exploring the impact of emigration on South African family life. The results suggest that the socio-psychological context within which the decision to emigrate is made is highly complex and involves a number of interlinked factors. Although emigrants are aware of the impact of their departure on the people and systems surrounding them, they need to cut themselves off psychologically from significant others in order to leave and socially disengage from the home country. Consequently, it is argued that emigration affects not only the people leaving, but also those left behind (and who, according to the findings of this study, do not generally benefit from the move). Therefore adequate psychological and practical preparation is recommended and the needs of elderly people left behind are highlighted.

Keywords: brain-drain, emigration, families, those left behind, transnational

Emigration is a life-changing decision. The existing literature suggests that emigrants face several challenges before and after emigration, related to intra- and interpersonal issues (for example, see Ainslie, 1998; Berry, 2001; Falicov, 2007; Glick, 2010; Sluzki, 1979). People's reasons for embarking upon such a life-altering journey differ. Historically, various circumstances, ranging from social to political and, increasingly, economic conditions, may force or inspire people to move from their country of origin. Today, people can move in and between countries with relative ease, thanks to modern technology and the knowledge that we essentially live in a global village.

South Africa is no stranger to emigration. It is often argued that recent emigration is a direct result of negative social and political factors, especially violent crime (Goldin, 2002; Horowitz \& Kaplan, 2001; Louw \& Mersham, 2001; Van Rooyen, 2000). However, the foreseeable sociopsychological impact of emigration has received limited attention (Marchetti-Mercer, 2009). Therefore this article describes the experiences of 10 South Africans prior to their departure from South Africa. It hopes to provide greater depth of perspective on the socio-psychological context of people who decide to emigrate.

\section{South African emigration}

An analysis of South African emigration in recent decades suggests that it has occurred in waves, often linked to specific political events during the apartheid years. However, emigration has continued after the democratic elections in 1994, and is frequently linked directly to increases in violent crime (Louw \& Mersham, 2001), poor service delivery coupled with corruption, and affirmative action (Goldin, 2002). Van Rooyen (2000) calls the exodus of white South Africans a new Great Trek, comparing South African emigrants to exiles, forced out of their country. He also contends that some people leave the country, whereas others only move to perceived "safer" areas of the country, and others emigrate "psychologically" to security complexes. Often those emigrating are portrayed negatively, and have been branded "traitors" to the new dispensation (Van Rooyen, 2000). Most South Africans have been affected by emigration, so the topic arouses deep interest. The question, "Should I stay or should I go?" has been called the defining question for today's South Africans (Richman, 2010).

A recent survey by Synovate (2008) suggests that, in 2008, 20\% of South Africans considered 
leaving the country. This figure dropped to $18 \%$ in 2009 because of the global recession. At least $30 \%$ in the 18 to 24 year-old age group were planning to emigrate. Violent crime and corruption $(82 \%)$ were given as the main reasons for emigrating. Factors such as the volatile economy (31\%), government problems (31\%) and wanting to have an experience in another country $(36 \%)$ were also highlighted. Reasons for staying were the climate (28\%), wanting to be close to family and friends $(23 \%)$ and a general love of South Africa (22\%).

The most popular destinations for South African emigrants are Australia, New Zealand, Canada, the United Kingdom and the United States (Crush, 2000). Although it has often been suggested that this is overwhelmingly a white phenomenon, black professionals have also emigrated and are increasingly looking for opportunities abroad (South African Institute for Race Relations [SAIRR], 2009). Valid statistics of how many people have left since 1994 are hard to find. Some data available indicate that most emigrants are between the ages of 24 and 40, and that about 750,000 young white South Africans have left since 1994 (SAIRR, 2009). This supports Crush's (2000) views that older people are less likely to emigrate, because they are less flexible professionally and socially, but it may also reflect the policies of destination countries discouraging older immigrants. Whatever the actual numbers and reasons, the social and economic impact of emigration is widespread - those leaving are often highly skilled, hence the reference to a "brain-drain" (Crush, 2000). Moreover, the phenomenon seems to have left an increasing number of elderly people behind with a reduced support system (Horowitz \& Kaplan, 2001; Marchetti-Mercer, 2009).

\section{Perspectives on emigration}

Recognising the circumstances behind the decision to emigrate may help understand the eventual experience of emigration (Hernandez \& McGoldrick, 1999). Some traditional perspectives emphasise push and pull factors (Kunz, 1973). Push factors are negative circumstances in the country of origin which propel people towards leaving, whilst pull factors are benefits perceived to be present in the destination country.

Bughra (2004) emphasises the importance of recognising whether the move is voluntary or involuntary in order to assess its impact on the individual and the family. People who migrate seeking economic or educational improvement tend to experience different stresses from those who are forced to leave. Moreover, people who are highly motivated to emigrate are less likely to experience mental health problems. How people adjust to the stresses of emigration may depend on personal and contextual factors (Ainslie, 2002). The concept of a "migrant personality" (Beneva \& Frieze, 2001, p. 480) proposes that emigrants have personality characteristics different from those of people who stay. Emigrants are claimed to be more work-orientated, have higher achievement and power motivation, with a lower affiliation motivation and family centrality.

Sluzki (1979) highlights specific phases of the migration process. Each has unique characteristics and triggers various coping mechanisms on the part of the family and brings about specific conflicts and symptoms. Different generations are likely to experience the move dissimilarly and a married couple may also adapt differently, possibly leading to some acculturative stress. Ali, Van der Zee, and Sanders (2003) believe that the stresses of emigration can test even a committed relationship, while Boyle, Kulu, Cooke, Gayle, and Clara (2006) warn that a marriage may dissolve unless both partners benefit equally from the move. Children and teenagers face specific challenges because they are not part of the decision to leave, and teenagers in particular face a number of developmental challenges, irrespective of the emigration (Grinberg \& Grinberg, 1989; Marchetti-Mercer, 2009).

White (2004) identifies three phases in what he terms the migration of identity. Firstly, there is a separation phase, involving a break from one's known life and characterised by optimism. Then, in the liminal phase, an "in-between" phase, one's familiar sense of being in the world is absent. It is marked by periods of disorientation and confusion, and even significant despair. Lastly, a reincorporation phase is achieved post-emigration when one has arrived at another place in life and experiences a sense of fitting in and being at home.

Ultimately, emigration implies loss: "The immigrant experience represents a special case of 
mourning in which mourning revolves around the loss of loved people and place" (Ainslie, 1998, pp. 285-286). Emigration can lead to "cultural mourning", where "cultural enclosures that have organized and sustained experience" (Ainslie, 1998, p. 287) are lost.

Modern technology may help negotiate the physical absence of loved ones (Baldassar, 2007; Falicov, 2007; Horst, 2006; Panagakos \& Horst, 2006; Wilding, 2006). It allows relationships to be maintained despite the distance (Baldassar, 2007; Falicov, 2007; Wilding, 2006). However, Mulder and Cooke (2009) point out that physical contact is important in maintaining relationships, and this cannot be so easily replaced by using technology. Return visits to the country of origin may also be a way to maintain relationships (Baldassar \& Baldock, 2000) and provide "emotional re-fuelling" (Akhtar, 1995, p. 1052).

Connections with a country of origin can be maintained via "remittances", financial support by emigrants to those left behind (Glick, 2010) in an attempt to maintain relational ties (Akesson, 2009). Immigrants may also attempt to cope with their losses by rebuilding their ethnic community networks in their destination countries (Falicov, 2007), which links to Ainslie's (1998) concept of "potential space" (p. 297). Connections to such community networks have been shown to correlate highly with mental health (Vega, Kolody, Valle, \& Weir, 1991).

People emigrating often face the potential loss of pets, which play a significant role in people's lives (Walsh, 2009). Interaction with pets contributes to psychological well-being, providing a sense of comfort and security during disruptive life transitions. Losing a pet in the midst of other losses such as migration may have a negative cumulative effect (Walsh, 2009).

Emigration is primarily a relational phenomenon (Falicov, 2007), so the experience of loss is not limited to those leaving. Family and friends remaining behind are also deeply affected (Marchetti-Mercer, 2010). Grinberg and Grinberg (1989) point out that those left behind may experience sorrow and depressive feelings, and be angry at those emigrating. Indeed, Falicov (1998) believes that because of their "forced passivity" (p. 59), they may suffer even more than those emigrating. Griffiths (2007) argues that those who emigrate must accept that their decision will leave a deep felt impact on those left behind; consequently, sharing the decision to leave with others may be very difficult.

In the face of all these factors, adequate, realistic psychological preparation is essential (Mirsky, 2004). Ward and Styles (2001) warn against inadequate preparation for such a major life event and not having a realistic perception of the psychological impact of the move. Many changes are necessary to create psychological bridges between the present and the past. Moreover, despite pre-preparation, problems may still be encountered in the new country (Ward \& Styles, 2001). People often idealize the destination country and "badmouth" the country they are leaving (Grinberg \& Grinberg, 1989), but a less idealized perception of their new life may buffer the inevitable stresses and disappointments associated with the move (Mirsky, 2004).

\section{RESEARCH APPROACH}

The following research questions underpinned the research project: 1 . How is recent South African emigration experienced in the context of the family and other social systems? 2. What social and psychological factors play a role in the decision to emigrate? The focus was on 10 adults about to emigrate and their experiences around the decision to leave South Africa; and the experiences of members of their families and/or close friends left behind. The results discussed here focus specifically on the second part of the research question.

This qualitative study consisted of semi-structured interviews and genograms that explored the experiences and family themes of 10 South African families from various cultural and socioeconomic groups around the decision of some of their members to emigrate. The study was conducted over a period of 18 months.

A case study approach was used with each family providing an individual case study. Case studies are a qualitative methodology which "facilitates exploration of a phenomenon within its context using a variety of data sources" (Baxter \& Jack, 2008, p. 544). It has been argued that case 
studies are particularly useful in answering "how" and "why" questions (Yin, 2003), as in this research study. A family systems perspective, which views the family as a network of interlocking relationships best understood from a transgenerational perspective (Goldenberg \& Goldenberg, 2008), allowed a relational perspective on emigration, augmented by the use of genograms.

\section{Sampling}

The initial participants in the study (people about to emigrate from South Africa) were identified using a purposive sampling approach. A preliminary sample of 10 families was identified and deemed large enough to obtain a wide range of responses, while allowing for in-depth exploration of each case (Willig, 2008). Snowball sampling was used, as some participants referred interviewers to other possible participants. Due to practical constraints, it was possible to interview only one member from each of the families emigrating. Therefore the results discussed in this article reflect that individual's experiences and perceptions and not necessarily those of other family members. Later, 21 family members and/or friends left behind were also interviewed six months after the departure of the emigrants, but their experiences are not described in this article.

The decision to recruit 10 families was affirmed during data analysis when saturation was reached, based on the responses from the preliminary sample, so additional data collection was considered unnecessary to expand or enrich the analysis. In the end, one of the original participants did not emigrate, as she fell ill and did not want to forgo all family support by emigrating. One family returned a few months later, and a follow-up interview was conducted with the initial participant.

Six of the white participants interviewed were Afrikaans-speaking, and three were Englishspeaking. The single black participant was Zulu-speaking. There were nine women and one man. The oldest was 54 years old and the youngest 32, with an average age of 39.2. All had professional qualifications - the majority were psychologists, followed by medical doctors (see demographics of participants interviewed in Table 1).

Table 1. Demographics of participants

\begin{tabular}{|c|c|}
\hline Gender & Women $(N=9)$, Men $(N=1)$ \\
\hline Age & $\begin{array}{c}32-54 \\
M=39.2, S D=1.928\end{array}$ \\
\hline Marital status & $\begin{array}{c}\text { Married }=7 \\
\text { Divorced }=1 \\
\text { Single }=2\end{array}$ \\
\hline Language preference in home & $\begin{array}{c}\text { English }=3 \\
\text { Afrikaans }=6 \\
\text { Zulu }=1\end{array}$ \\
\hline Profession & $\begin{array}{c}\text { Teacher }=1 \\
\text { Educational Psychologist }=1 \\
\text { Counselling Psychologist }=2 \\
\text { Medical Doctor }=2 \\
\text { Academic }=1 \\
* * \text { Clinical Psychologist }=3\end{array}$ \\
\hline Destination country emigrated to as a family & $\begin{array}{c}\text { United Kingdom }=1 \\
\text { Canada }=2 \\
\text { New Zealand }=6^{*} \\
\text { United States of America }=1\end{array}$ \\
\hline
\end{tabular}

**NB: 9 out of 10 of the participants were women. One participant was male, 32 years old, single, and a Clinical Psychologist.

*NB: One participant planned to emigrate to New Zealand but terminated the move due to illness 
The majority left with their families for New Zealand (five), followed by Canada (two), one for the UK, and one for the USA. The participant who decided not to leave had planned to go to New Zealand.

\section{Data collection}

The interviews were carried out by the author and two research assistants. Interviews were conducted by a single interviewer at a time and lasted about one to one-and-a-half hours. Inter-interviewer reliability was ensured by regular discussions amongst the different interviewers, prior to and after interviews, and detailed process notes. All the participants completed a consent form before being interviewed, after the project had received the necessary ethical clearance following the protocols of the University of Pretoria. For those emigrating, questions explored the personal, interpersonal and social motivations around the decision to emigrate. However, there was some flexibility around the questions, as interviewers explored issues further than the basic interview format. The genogram information provided insight into the relational dynamics and relevant family themes. Interviews were digitally recorded and transcribed verbatim.

\section{Data analysis}

Firstly, existing literature on emigration was reviewed to inform the process of compiling interview questions and choosing how to analyse the data. The analysis was both inductive (themes were generated from the data collected) and deductive (data gained meaningful interpretation in relation to existing theories of emigration).

Thematic analysis was chosen as a useful method to conduct qualitative analysis, because it is a flexible way to identify, analyse and report data patterns. Braun and Clarke's (2006) framework was used. The following steps were taken:

- Phase 1: Familiarising myself with the data (data were transcribed, read, re-read, and the most prominent ideas noted).

- Phase 2: Generating initial codes (systematic coding of interesting features using the entire data set, collating data relevant to each code).

- Phase 3: Searching for themes (collating codes into potential themes; gathering all data applicable to each potential theme).

- Phase 4: Reviewing themes (checking themes to see if they worked in relation to the coded extracts (Level 1) and the entire data set (Level 2); then generating a thematic "map" of the analysis).

- Phase 5: Defining and naming themes (ongoing analysis to refine the specifics of each theme, and the overall story of the analysis, generating definite definitions and names for each theme).

- Phase 6: Producing the report (selecting engaging examples of responses, and final analysis of selected extracts; relating the analysis back to the research question and existing literature).

Genogram analysis was carried out according to the approach recommended by Like, Rogers, and McGoldrick (1988), addressing issues such as family structure, family life cycle, pattern repetition in families across generations, life experiences, family relational patterns and family balance and imbalance.

\section{Ensuring the quality of the research}

After a preliminary analysis, evidence which did not support the themes identified in the first analysis was sought in the data. The themes which still emerged were then identified as the main ones reflecting the experiences of those emigrating (Chu Huang \& Mathers, 2008). Using as many verbatim excerpts as possible from the participants themselves was a way of supporting the credibility of the analytical claims or achieving referential adequacy (Morrison \& James, 2009).

Reflexivity was part of the process and other fellow academics were included as "critical 
friends" to engage others in the interpretations reached. Therefore other interpretations outside the author's own subjective perspectives were used to challenge and extend the author's interpretations.

\section{FINDINGS}

The results discussed below focus solely on the experiences of the participants interviewed who were about to emigrate (the names have been changed to ensure confidentiality). Furthermore, there is no indication of how the family eventually adapted in the country of destination, as a follow-up interview was carried out with the initial participant only in the case of the one family that returned.

The following ten main themes were identified:

- Reasons for leaving

- Expectations around the destination country

- The manner of the decision

- Permanence of the decision

- Work prospects in the destination country

- Impact of the decision to emigrate

- Preparation for emigration

- $\quad$ Farewells and saying good-bye

- $\quad$ Perceived losses associated with leaving South Africa

- $\quad$ Planned manner of maintaining contact with people in South Africa

Next, the descriptive summaries are presented.

\section{Reasons for leaving}

Although socio-political factors and concerns around safety were mentioned in a couple of instances — for example, by Terri, who said that "[s] uddenly you realize you are a frog in boiling water" only one family among the participants reported emigrating after traumatic exposure to crime. In many responses, a need for change was prominent - "We need to reboot the system" (Pam); "I want to spread my wings" (Thembi) — as was providing better opportunities for one's children. Other significant responses highlighted a sense of no longer belonging among Afrikaans participants: "There is no place for my culture in South Africa" (Cecilia). There was a fear of HIV/AIDS infection in the Zulu-speaking family: "We wish we could raise our children in a way whereby we're not so paranoid about this HIV/AIDS. It is also a very big motivation" (Thembi).

\section{Expectations around the destination country}

Many participants were confident that they would lead safer and less stressful lives once they emigrated. There were many expectations regarding future benefits for the children, especially in terms of education and general lifestyle: "... it will be the first time in their lives that they will be able to ride bikes in the streets and walk to school" (Terri). Several mothers hoped they would have more time to spend with their children: "So I hope that I can reduce my focus to family" (Pam).

\section{The manner of the decision}

The decision to emigrate was made primarily by both partners in a couple. In some instances, the decision was initially driven by one partner who had to convince the other partner.

Children were involved in discussions where this was age-appropriate, but were not part of the decision. Extended family members and friends were only informed once the final decision had been made. In some cases, the decision to emigrate was taken over a long time, even years. In others, the decision was very quick, mostly linked to a job opportunity that arose; only in one case was it made directly after being exposed to crime.

In one instance the decision to emigrate led to the break-up of a long-term relationship and in another the decision was made following a break-up (in this case, a sudden illness led to the reversal of the decision to emigrate). 


\section{Permanence of the decision}

There appeared to be some differences on how people saw the permanence of their decision. Some were adamant that it was important to be committed to the decision: "Ifyou're hesitant, you will fail" (Pam). Others preferred to keep a back door open: "I am not thinking that if we are absolutely miserable and we hate it, that we can't come back" (Nadia).

\section{Work prospects in the destination country}

Most of the people interviewed had already secured work in their country of destination or felt that it would be easy to secure a job once they were there. In four of the case studies, the emigration was based on the wife's job opportunity. In one instance, the family eventually returned to South Africa because the husband could not find suitable employment.

\section{Impact of the decision to emigrate}

Reactions from family and friends

Participants experienced mixed reactions from people when they shared the news of the impending emigration. Reactions varied from being supportive and understanding: "My parents are very supportive ..., they say... You ... are doing the right thing" (Estelle), to anger and disbelief: "She told me I am running away from my people" (Thembi). Some participants received mixed responses, especially from parents: "She's putting on a brave face...but every now and again she gets teary" (Terri); “My mom keeps saying 'Go' but I think that's what mothers are supposed to do" (Cathy).

Perceived social impact of the decision

All the participants seemed aware of the impact that their departure would have on people around them. Most people with older parents were concerned about leaving them behind, especially if this would mean reduced social support. Some understood the impact of their move on their social circle: "I thought it was something that I was doing, but when you uproot a tree you leave a big hole in the forest..., which won't be filled" (Pam). Participants in helping professions experienced a sense of guilt towards their patients: "It's a huge loss for our colleagues, and for our patients" (Terri); "I'm supposed to be helping, and now I'm actually in some way contributing to their pain" (Pam).

Many thought that their decision to emigrate had triggered similar processes in the people around them: "So our going has kind of lit a fire in them, ... they are now far more ambivalent than they were before"(Pam); "Everyone who has attachments or partners or wives...they're all leaving" (Cecilia).

\section{Preparation for emigration}

After people made the final decision to emigrate, a number of psychological and practical processes took place.

In a technology driven society the internet seems to be a great source of information. In some instances, participants visited their destination country before making a final decision. Some families also had some international exposure prior to deciding to emigrate. People with children prepared them by providing a lot of practical information in order to alleviate anxiety. Some felt unsure about how to prepare for what lay ahead: "It's impossible to prepare for emigration as you have never done it before" (Terri).

Packing up one's belongings was a painful issue for many people, although in the end there seemed to be a sense of relief and freedom: "It's gone. And if it were to fall off the ship, it's gone... stuff is not important" (Nadia). The weight was literally off their shoulders: "I've got nothing now but money...., it gives me a feeling of freedom" (Clive).

There seemed to be a process of disengagement prior to leaving the country: "I personally experienced a complete detachment. So by the time I leave, I am not even a South African anymore" (Cecilia); "You have to detach without reattaching, you're rootless" (Pam). There was also a sense of becoming less emotionally invested in what was happening in the country: "You dissociate so 
badly from what you see around yourself" (Cecilia); “... you stop investing in new relationships" (Elize).

People experienced divergent feelings: "I go from kind of anxiety and fear of the unknown to excitement and thinking that this is a great fresh start" (Nadia).

\section{Farewells and saying good-bye}

A painful part of the phase prior to departure was saying good-bye: "Obviously I have cried a lot" (Elize). Consequently many felt a need to spend more time with loved ones: "... spending time with people, closing off relationships in a good way, maintaining ties that are going to last the distance" (Pam). Some held farewell parties, while others found other ways to take leave of the country and their loved ones: "We are busy getting together with more friends than before because we know we're only going to have two months left" (Terri).

\section{Perceived losses associated with leaving}

A number of interpersonal losses were identified, especially where elderly people were concerned: "It's the acknowledgement that I might not see my mom again ... if I say goodbye, it might be the last time" (Elize).

Many people were distressed about having to leave their pets behind. Some families could not afford to take their pets with them, and/or were limited by stringent quarantine laws: "It was incredibly traumatic...we thought about taking the pets, but it's usually expensive" (Pam). However, some decided to make the financial and practical investment: "She's part of the family. They'll make you feel like wherever you are is home. So I think it's important, just to help you settle in there" (Nadia). This was done especially when children were involved: "Well, I asked my son whether we could leave the dog here, he burst out into tears, so I just decided I can 't leave the dog here" (Elize).

There was also a strong sense of loss about having to leave one's roots behind: "Eish, home ... home sweet home" (Thembi); "It is difficult ... you leave your culture, you leave Africa, ... there is so much that we are used to, that we take for granted...sunshine. ...the feeling of being home" (Cecilia).

Only in a couple of instances was the impact of the loss of domestic support mentioned.

\section{Planned manner of maintaining contact with people in South Africa}

Overall, participants thought that technology, especially tools such as Skype, would allow them to stay in close contact with those back home. They seemed to experience some comfort in the fact that such means would allow them effortless and constant contact, saying "... yes, it would be much harder to do it if we didn't have that reassurance..." (Pam) and "...we'll be able to have lots of contact which I think makes things better because I think you're much closer" (Terri). However, there was some awareness that using technology might be difficult for older people: "I bought my parents a laptop, and they have been practising.... And I think it's alleviated the anxiety" (Estelle).

Regular visits back to South Africa were generally not seen as a viable option, because of the financial constraints as well as the complexity of such trips.

\section{DISCUSSION}

The results of this study suggest that a number of social and psychological factors play a role in the decision to emigrate. As far as the profile of the participants is concerned, the average age of those interviewed was the late thirties. They were all professional people, in many instances highly skilled, which is consistent with the already reported phenomenon of a "brain drain" (Crush, 2000). The majority of the psychologists left for New Zealand, and two medical doctors left for Canada, often a popular destination for South African doctors (Bezuidenhout, Joubert, Hiemstra, \& Struwig, 2009).

The majority of families that left (seven) had relatively young children, which may have played a role in the decision to move. The children's perceived vulnerability and the fact that (with one exception) the children were still pre-teens may have made it seem like the most practical time to 
move. It would be valuable to explore the long-term adaptation of these children, given that they were not part of the decision to emigrate and may have experienced the transition quite differently from the way the adults did (Grinberg \& Grinberg, 1989).

Understanding the motivation behind the decision to emigrate may be valuable, because it is likely to affect eventual adaptation. Emigrants convinced they are being pushed out of their country may experience additional problems and stress (Bughra, 2004).The participants' varied responses suggest that there is no single reason driving people to emigrate, but rather a complex interaction of factors. Push factors varied from some concerns about socio-political issues and safety, as expected by Van Rooyen (2000) and Griffiths (2007), although it was identified as the primary reason for emigrating only in one case, to fear of HIV/AIDS (reported by the Zulu-speaking participant), and a sense of no longer belonging (reported by a number of Afrikaans-speaking participants, who felt they were associated with the previous regime, with little future in South Africa - interestingly, despite not feeling at home in South Africa, they chose an English-speaking country where the issue of belonging might remain relevant). There were also some prominent pull factors, such as a need for change and a desire for better opportunities for the family.

Mostly, the decision to emigrate was made jointly by the couple. In the instances where one partner was more committed to the move than the other, one may speculate on the effect on the long-term success of the emigration The potential threat to a couple's relationship arising from the stresses of emigration has been highlighted by Ali et al. (2003) and Boyle et al. (2006). The fact that in one case the couple split up prior to the emigration and only one partner emigrated, and that one family returned to South Africa because the husband could not find suitable employment, suggests that both partners should be equally committed to the move. Disparities in career prospects and satisfaction may place undue strain on relationships, so expectations and prospects should be carefully negotiated prior to departure.

Generally people's expectations of the destination country were optimistic and were linked to their reasons for leaving - they hoped to improve their quality of life, have more freedom of movement under safer conditions and better opportunities for their children. Possibly an over-idealized view of the changes linked to emigration may eventually lead to disappointment (Mirsky, 2004). Follow-up interviews would be the only way to determine whether the reality of the migration matched initial expectations.

Participants held different views regarding the permanence of their decision. One can only speculate about which approach leads to a more "successful" emigration. Being fully committed to the process may buffer some of the stresses likely to be encountered, but keeping options open may be helpful in case the family wishes to return but may be afraid of losing face.

Generally people received mixed responses from family and friends when the emigrants informed them of their decision. This finding is in line with the literature, which indicates that those left behind may experience a number of negative feelings (Falicov, 1998; Griffiths, 2007; Grinberg \& Grinberg, 1989; Marchetti-Mercer, 2010). However, it was significant that most participants appeared to be very sensitive to the impact of their decision on the people around them, which may have led them to informing others only once the final decision had been made, as suggested by Griffiths (2007).

The main losses identified were linked to relationships, especially where elderly people are left behind. There were deep concerns about not being able to see elderly parents again. The negative impact of their adult children's emigration on elderly people in South Africa has already been identified as a serious social problem (Horowitz \& Kaplan, 2001; Marchetti-Mercer, 2010). Furthermore, people in the helping professions seemed cognizant of the negative impact of their departure on patients and colleagues. This overall interpersonal awareness and the obvious importance placed on interpersonal relationships seem to contradict the claims of Beneza and Frieze (2001), who argue that people who emigrate have a lower family centrality.

Some participants expressed sadness at having to leave Africa and their roots, which echoes Ainslie's (1998) views on "cultural mourning" and its profound impact on the lives of emigrants. 
There were also noticeable emotions around the loss of pets. In some instances, people went to great lengths and expense to take their animals with them. This confirms Walsh's (2009) views on the important role of pets in a family and how they can assist through difficult transitions.

Few participants mentioned the loss of domestic support. Given the fundamental change that this would mean in terms of most South Africans' daily routines, one would have expected more concern around this issue.

The role that technology would play in staying in contact was highlighted by all the participants. This is in line with current research on transnational links (Baldassar, 2007; Falicov, 2007; Horst, 2006; Wilding, 2006). Regular visits were not perceived as practically viable, given the financial and logistic implications, which may pose a challenge in future, because it does not allow for "emotional re-fuelling" (Akhtar, 1995, p. 1052) or provide a space for maintaining relationships (Baldassar \& Baldock, 2000). Many thought that their decision to emigrate had triggered similar questions in other people. This reflects the prevailing "Should I stay or should I go?" debate already highlighted by Richman (2010).

In general, the period prior to emigration was characterised by practical arrangements and demands, followed by a process of psychological disengagement (White, 2004), during which people started taking leave of their loved ones. Accordingly, time was spent with family and friends and some participants held farewell parties. This points to an awareness of the impending loss of relationships unlikely to be easily replaced (Ward \& Styles, 2001), as well as wanting to obtain proper emotional closure.

Some visited the country of destination before emigrating, but the majority left without ever having visited these countries and some did so without having secured proper employment. One can only speculate on the impact of inadequate practical and psychological preparation (Ward \& Styles, 2001 ) in these participants' eventual adaptation.

\section{CONCLUSION}

The results of this study, although they were limited to a small sample, suggest that the phenomenon of South African emigration requires a multi-layered perspective, because it is not exclusively driven by the prevailing socio-political factors.

In the final analysis, the decision to leave seems based on the immediate benefits for the nuclear family or emigrating individuals. Although those emigrating may be sensitive to the negative impact of the move on those left behind, it may be impossible to consider the emotional needs of people outside the immediate nuclear unit if that unit emigrates. This requires an emotional cutting off from other meaningful relationships, which those left behind may experience intensely. Ultimately, emigration is never solely an individual event, but must be regarded as a relational phenomenon (Falicov, 2007).

Significantly, South African emigration seems to hold few advantages for those left behind, and may predominantly have negative social and psychological effects for them (Marchetti-Mercer, 2010), in contrast to some international trends where those left behind may benefit financially from remittances (Glick, 2010).

This study alerts those considering emigration to engage in proper psychological preparation and to the need to acknowledge and respect the position of those staying behind. Ways of maintaining the relationship with those left behind and the role which technology may play in this process should also be explored and negotiated prior to departure. In the case of elderly parents, the kinds of practical challenges the parents may face should be explored, and the possibility of seeking support from others in a similar plight should be considered.

It is hoped that the results of this study will lead to further research on the experiences of South Africans who emigrate, and has highlighted the need to explore the level of psychological adaptation of expats living abroad.

\section{ACKNOWLEDGEMENT}

The material is based on work supported by the National Research Foundation (NRF). 


\section{REFERENCES}

Ainslie, R. C. (1998). Cultural mourning, immigration, and engagement: Vignettes from the Mexican experience. In M. Suarez-Orozco (Ed.), Crossings: Mexican immigration in interdisciplinary perspectives (pp. 285-300). Cambridge, MA: Harvard University Press.

Ainslie, R. C. (2002). The plasticity of culture and psychodynamic and psychosocial processes in Latino immigrant families. In M. Suarez-Orozco \& M. Páez (Eds.), Latinos: Remaking America (pp. 289-300). Berkeley, CA: University of California Press.

Akesson, L. (2009). Remittances and inequality in Cape Verde: The impact of changing family organization. Global Networks, 9, 381-398.

Akhtar, S. (1995). A third individuation: Immigration, identity and the psychoanalytic process. Journal of the American Psychoanalytic Association, 43, 1051-1084.

Ali, A., Van der Zee, K., \& Sanders, G. (2003). Determinants of intercultural adjustment among expatriate spouses. International Journal of Intercultural Relations, 27, 563-580.

Baldassar, L. (2007). Transnational families and aged care: The mobility of care and the migrancy of ageing. Journal of Ethnic and Migration Studies, 33, 275-297. doi:10.1080/13691830601154252

Baldassar, L., \& Baldock, C. (2000). Linking migration and family studies: Transnational migrants and the care of ageing parents. In B. Agozino (Ed.), Theoretical and methodological issues in migration research (pp.61-85). Aldershot, UK: Ashgate.

Baxter, P., \& Jack, S. (2008). Qualitative case study methodology: Study design and implementation for novice researchers. The Qualitative Report, 13, 544-559.

Beneva, B. S., \& Frieze, I. H. (2001). Toward a concept of a migrant personality. Journal of Social Issues, $57,477-491$.

Berry, J. W. (2001). A psychology of immigration. Journal of Social Issues, 57, 615-631.

Bezuidenhout, M. M., Joubert, G., Hiemstra, L. A., \& Struwig, M. C. (2009). Reasons for doctor migration from South Africa. SA Family Practice, 51, 211-215.

Boyle, P. J., Kulu, H., Cooke, T., Gayle, V., \& Clara, H. M. (2006). The effect of moving on union dissolution. Max Planck Institute for Demographic Research: Working Paper (WP 2006-002). Rostock, Germany: MPIDR.

Braun, V., \& Clarke, V. (2006). Using thematic analysis in psychology. Qualitative research in Psychology, $3,77-101$.

Bughra, D. (2004). Migration and Mental Health. Acta Psychiatrica Scandinavia, 109, 243-258.

Chu Huang, Y., \& Mathers, N. J. (2008). Postnatal depression and the experience of South Asian marriage migrant women in Taiwan: Survey and semi-structured interview study. International Journal of Nursing Studies, 45, 924-931. doi:10.1016/j.ijnurstu.2007.02.006

Crush, J. (2000). Losing our minds: Skills migration and the South African brain drain. Migration Policy Series No. 18. Southern African Migration Project. Cape Town, South Africa: Idasa.

Falicov, C. J. (1998). Journeys of migration: Opportunity and continuity. In C. Falicov (Ed.), Latino families in therapy (pp. 46-66). New York, NY: Guilford.

Falicov, C. J. (2007). Working with transnational immigrants: Expanding meanings of family, community, and culture. Family Process, 46, 157-171.

Glick, J. E. (2010). Connecting complex processes: A decade of research on immigrant families. Journal of Marriage and Family, 72, 498-515.

Goldin, J. (2002). Belonging to two worlds: The experience of migration. South African Psychiatric Review, $5,4-8$.

Griffiths, C. G. (2007). Narratives of immigration: Negotiating transition. Unpublished PhD thesis, University of South Africa, Pretoria, South Africa.

Grinberg, L., \& Grinberg, R. (1989). Psychoanalytic perspectives on migration and exile. London, UK: Yale University Press.

Goldenberg, H., \& Goldenberg, I (2008). Family therapy: An overview. Belmont, CA: Thomson \& Brooks/Cole.

Hernandez, M., \& McGoldrick, M. (1999). Migration and the life cycle. In B. Carter \& M. McGoldrick (Eds.), The expanded family life cycle: Individual, family and social perspectives (3rd ed., pp. 169-184). Boston, MA: Allyn and Bacon.

Horowitz, S., \& Kaplan, R. D. E. (2001). The Jewish exodus from the new South Africa: Realities and implications. International Migration, 39, 3-32.

Horst, H. A. (2006). The blessings and burdens of communication: Cell phones in Jamaican transnational 
social fields. Global Networks, 6, 143-159.

Kunz, E. F. (1973). The refugee in flight: Kinetic models and forms of displacement. International Migration Review, 7, 125-146.

Like, R. C., Rogers, J., \& McGoldrick, M. (1988). Reading and interpreting genograms: A systematic approach. Journal of Family Practice, 26, 407-412.

Louw, P. E., \& Mersham, G. (2001). Packing for Perth: The growth of a Southern African diaspora. Asian and Pacific Migration Journal, 10, 303-333.

Marchetti-Mercer, M.C. (2009). South Africans in flux: Exploring the mental health impact of migration on family life. African Journal of Psychiatry, 12, 129-134.

Marchetti-Mercer, M.C. (2010). Relational bereavement in emigration: Those staying behind. Poster presented at EFTA Conference, Paris (France), October 2010.

Mirsky, J. (2004). Preparing adolescents for immigration: A group intervention. Children and Youth Services Review, 26, 413-425.

Morrison, M., \& James, S. (2009). Portuguese immigrant families: The impact of acculturation. Family Process, 48, 151-166.

Mulder, C. H. \& Cooke, T.J. (2009). Family ties and residential locations. Population, Space and Place, 15, 299-304.

Panagakos, A. N., \& Horst, H. (2006). Return to cyberia: Technology and the social worlds of transnational migrants. Global Networks, 6, 109-124.

Richman, T. (Ed.). (2010). Should I stay or should I go? To live in or leave South Africa. Cape Town, South Africa: Two Dogs.

Sluzki, C. E. (1979). Migration and family conflict. Family Process, 18, 379-390.

South African Institute for Race Relations [SAIRR]. (2009, 23 February). Skills flights retards growth and investment. Retrieved from: http://www.sairr.org.za.

Synovate. (2008). Should I stay or should I go? Synovate survey reveals South African attitudes towards emigration. (E-mail from KateSlade@synovate.com, 21 May 2008).

Van Rooyen, J. (2000). The new Great Trek: The story of South Africa's white exodus. Pretoria, South Africa: Unisa Press.

Vega, W. A., Kolody, B., Valle, R., \& Weir, J. (1991). Social networks, social support, and their relationship to depression among immigrant Mexican women. Human Organization, 50, 154-162.

Walsh, F. (2009). Human-animal bonds I: The relational significance of companion animals. Family Process, 48, 462-480.

Ward, C., \& Styles, I. (2001). Facilitating migrant settlement: Strategies for education. Retrieved from: http://www.aare.edu.au/01pap/war01232.htm.

White, M. (2004). Challenging the culture of consumption: Rites of passage and communities of acknowledgement. Dulwich Centre Newsletter, $2 \&$ 3, 38-47. Retrieved from: http://www.dulwichcentre.com.au/challenging-the-culture-of-consumption.html.

Wilding, R. (2006). "Virtual intimacies"? Families communicating across transnational contexts. Global Networks, 6, 125-142.

Willig, C. (2008). Discourse analysis. In J.A. Smith (Ed.), Qualitative psychology. A practical guide to research methods (pp. 159-183). Thousand Oaks, CA: Sage.

Yin, R. K. (2003). Case study research: Design and methods (3rd ed.). Thousand Oaks, CA: Sage. 